DOT/FAA/AM-11/10

Office of Aerospace Medicine

Washington, DC 20591

\title{
Fatigue Risk Management in Aviation Maintenance: Current Best Practices and Potential Future Countermeasures
}

Alan Hobbs

San Jose State University

NASA Ames Research Center

Moffett Field, CA 94035

Katrina Bedell Avers

Civil Aerospace Medical Institute

Federal Aviation Administration

Oklahoma City, OK 73125

John J. Hiles

Flight Standards Division

Federal Aviation Administration

Washington, DC 20591

June 2011

Final Report 


\section{NOTICE}

This document is disseminated under the sponsorship of the U.S. Department of Transportation in the interest of information exchange. The United States Government assumes no liability for the contents thereof.

This publication and all Office of Aerospace Medicine technical reports are available in full-text from the Civil Aerospace Medical Institute's publications Web site: www.faa.gov/library/reports/medical/oamtechreports 
Technical Report Documentation Page

\begin{tabular}{|c|c|c|c|c|}
\hline $\begin{array}{l}\text { 1. Report No. } \\
\text { DOT/FAA/AM-11/10 }\end{array}$ & \multicolumn{2}{|c|}{ 2. Government Accession No. } & \multicolumn{2}{|c|}{ 3. Recipient's Catalog No. } \\
\hline \multicolumn{3}{|c|}{$\begin{array}{l}\text { 4. Title and Subtitle } \\
\text { Fatigue Risk Management in Aviation Maintenance: Current Best } \\
\text { Practices and Potential Future Countermeasures }\end{array}$} & \multicolumn{2}{|c|}{$\begin{array}{l}\text { 5. Report Date } \\
\text { June } 2011\end{array}$} \\
\hline \multicolumn{3}{|l|}{ 7. Author(s) } & \multicolumn{2}{|c|}{ 8. Performing Organization Report No. } \\
\hline \multicolumn{3}{|c|}{$\begin{array}{l}{ }^{1} \text { San Jose State University } \\
\text { NASA Ames Research Center } \\
\text { Moffett Field, CA } 94035\end{array}$} & \multicolumn{2}{|c|}{ 10. Work Unit No. (TRAIS) } \\
\hline \multicolumn{3}{|c|}{$\begin{array}{l}{ }^{2} \text { FAA Civil Aerospace Medical Institute } \\
\text { Oklahoma City, OK } 73125\end{array}$} & \multirow{2}{*}{\multicolumn{2}{|c|}{ 11. Contract or Grant No. }} \\
\hline \multicolumn{3}{|c|}{$\begin{array}{l}{ }^{3} \text { FAA Flight Standards Division } \\
\text { Washington, DC } 20591\end{array}$} & & \\
\hline \multicolumn{3}{|c|}{ 12. Sponsoring Agency name and Address } & \multicolumn{2}{|c|}{ 13. Type of Report and Period Covered } \\
\hline \multicolumn{3}{|c|}{$\begin{array}{l}\text { Office of Aerospace Medicine } \\
\text { Federal Aviation Administration } \\
800 \text { Independence Ave., S.W. } \\
\text { Washington, DC } 20591\end{array}$} & 14. Sponsoring & \\
\hline \multicolumn{5}{|c|}{$\begin{array}{l}\text { 15. Supplemental Notes } \\
\text { Work was accomplished under approved task AM-A-08-HRR-521 }\end{array}$} \\
\hline \multicolumn{5}{|c|}{$\begin{array}{l}\text { 16. Abstract } \\
\text { The unregulated hours and frequent night work characteristic of maintenance can produce significant levels of } \\
\text { employee fatigue, with a resultant risk of maintenance error. Fatigue Risk Management Systems (FRMS) are } \\
\text { widely used to manage fatigue among flight crew and drivers of commercial vehicles, but comprehensive } \\
\text { approaches to fatigue risk management are still uncommon within maintenance organizations. In the wider } \\
\text { transport industry, the objective of most FRMS has been to reduce fatigue to an acceptable level. Two additional } \\
\text { objectives can be identified for FRMS in the maintenance environment: reducing or capturing fatigue-related } \\
\text { errors, and minimizing the harm caused by fatigue-related errors. A range of countermeasures can help to achieve } \\
\text { these three objectives in aviation maintenance. Some of these countermeasures are currently being applied within } \\
\text { the industry, while others may become feasible in the future. } \\
\text { The data available on best practices for fatigue risk management in aviation maintenance are continually } \\
\text { evolving. This should be considered an interim report. }\end{array}$} \\
\hline \multicolumn{2}{|c|}{$\begin{array}{l}\text { 17. Key Words } \\
\text { Maintenance, Human Fatigue, Alertness, Fatigue Risk } \\
\text { Management, FRMS, Countermeasures, Hours-of-Service }\end{array}$} & \multicolumn{3}{|c|}{$\begin{array}{l}\text { 18. Distribution Statement } \\
\text { Document is available to the public through the } \\
\text { Defense Technical Information Center, Ft. Belvoir, VA } \\
\text { 22060; and the National Technical Information } \\
\text { Service, Springfield, VA 22161 }\end{array}$} \\
\hline $\begin{array}{l}\text { 19. Security Classif. (of this report) } \\
\text { Unclassified }\end{array}$ & $\begin{array}{r}\text { 20. Security Classif. (of this pag } \\
\text { Unclassifie }\end{array}$ & & $\begin{array}{l}\text { 1. No. of Pages } \\
30\end{array}$ & 22. Price \\
\hline
\end{tabular}

Form DOT F 1700.7 (8-72)

Reproduction of completed page authorized 



\section{PREFACE}

"I have been a lead mechanic for over 25 years for the airlines. Have I ever worked tired when I shouldn't have, or seen others who worked tired when they shouldn't have? Yes. Do other mechanics, leads, and management know about it? Yes. Have mistakes been made due to fatigue? Yes.... When errors are made, we catch them, and repair them, and press on with the job. We don't document them. We simply fix them."

—Anonymous maintenance technician

This matter-of-fact statement made by an anonymous maintenance technician illustrates both the prevalence of fatigue and the current strategy that is used by many technicians in the aviation maintenance industry. Fatigue can affect all maintenance tasks via impaired judgment, difficulty focusing attention, memory lapses, reduced mood and motivation, and other performance effects. The reduction of aviation accidents and incidents caused by fatigue is one of the issues on the National Transportation Safety Board's (NTSB's) list of "most wanted" safety improvements. In 1997, the Board recommended that the Federal Aviation Administration "Review the issue of personnel fatigue in aviation maintenance; then establish duty time limitations consistent with the current state of scientific knowledge for personnel who perform maintenance on air carrier aircraft" (NTSB, 1997). The NTSB has also urged the FAA to provide guidance to maintenance personnel on the issue of fatigue.
There is an extensive literature on fatigue in the transportation industry (Dinges, 1995; Mitler, Carkadon, Czeisler, Dinges \& Graeber, 1988), including several FAA studies on fatigue in maintenance (Hackworth, Holcomb, Banks, Schroeder, \& Johnson, 2007; Johnson, Mason, Hall \& Watson, 2001). Much has also been written about fatigue risk management (Fourie, Holmes, Bourgeois-Bougrine, Hilditch, \& Jackson, 2010); however, there has been a lack of information on fatigue countermeasures specific to aviation maintenance. This document is intended to provide an overview of solutions to the problem of fatigue in the aviation maintenance environment. Some of these solutions are currently being applied. Others are potential countermeasures that may become feasible in the future. 



\section{ACKNOWLEDGMENTS}

This report was supported and partially funded by the FAA Air Traffic Organization Human Factors Research and Engineering Group. Work was accomplished under approved task AM-A-08-HRR-521.

We thank the many people who contributed to this report, and acknowledge the assistance provided by members of the FAA Maintenance Fatigue Work Group. 



\section{CONTENTS}

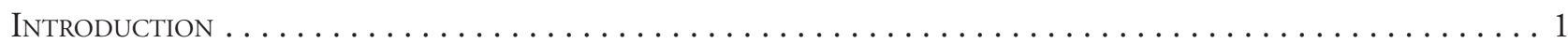

Fatigue Risk Management Principles $\ldots \ldots \ldots \ldots \ldots \ldots \ldots \ldots \ldots \ldots \ldots \ldots \ldots \ldots \ldots \ldots \ldots \ldots \ldots \ldots \ldots \ldots \ldots$

Characteristics of Maintenance Work That can Assist With Fatigue Management . . . . . . . . . . 1

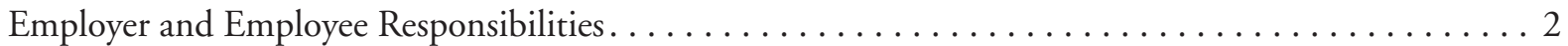

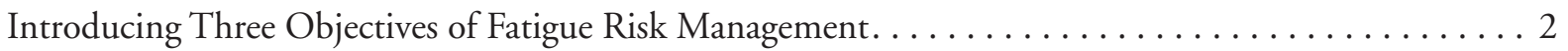

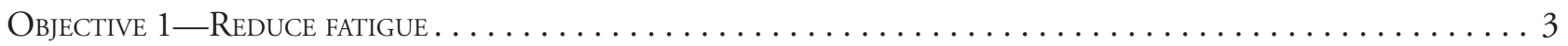

Hours of Service Limits Imposed by Aviation Authorities . . . . . . . . . . . . . . . . 3

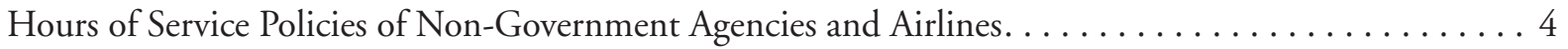

Scientific Scheduling Models . . . . . . . . . . . . . . . . . . . . . . . . . 5

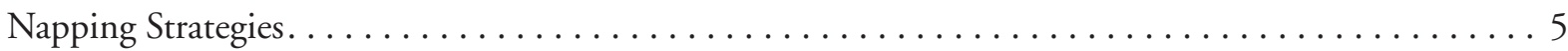

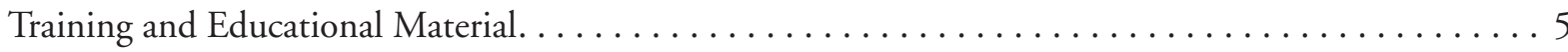

Excused Absences. ................................... 6

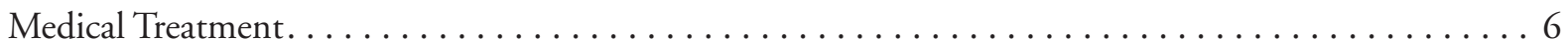

Objective 2 -Reduce or Capture Fatigue-Related Errors $\ldots \ldots \ldots \ldots \ldots \ldots \ldots \ldots \ldots \ldots \ldots \ldots$

Measures Directed Towards Individuals . . . . . . . . . . . . . . . . . . . . . . . . 7

Measures Directed Towards At-Risk Tasks $\ldots \ldots \ldots \ldots \ldots \ldots \ldots \ldots \ldots \ldots \ldots \ldots \ldots$

Objective 3 -Minimizing the Harm Caused by Fatigue-Related Errors $\ldots \ldots \ldots \ldots \ldots \ldots \ldots \ldots \ldots \ldots$

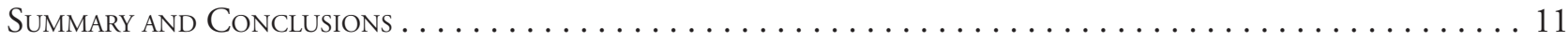

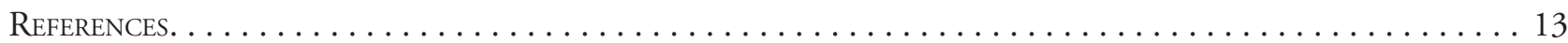

Appendix A: Model Rest and Duty Limitations for Persons Performing Maintenance Functions on AOC Holder Aircraft. . . . . . . . . . . . . . . . . . . . . . . . . . . . . . . A1

ApPENDIX B: Folkard's (2003) recommendations on Aircraft Maintenance Hours of Service. . . . . . . . . . B1

ApPEndix C: International Federation of Airworthiness Recommendations on Duty Times for

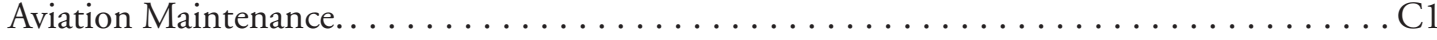

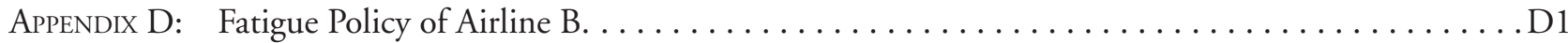

Appendix E: A Fatigue Risk-Assessment System in use by a Maintenance Organization. . . . . . . . . . . . . E1

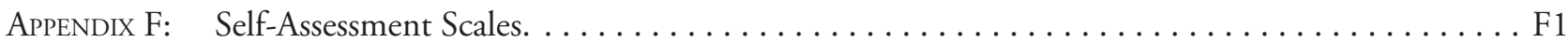

Appendix G: International Federation of Airworthiness Fatigue Control Recommendations.. . . . . . . . G1 



\section{LIST OF ACRONYMS}

\section{Acronym ----- Definition}

AMC---------- Acceptable Means of Compliance

AMT --------- Aircraft Maintenance Technician

AOG ----------Aircraft on Ground

CAA---------- Civil Aviation Authority (UK)

CAAC ------- Civil Aviation Administration of China

CAP --------- Civil Aviation Publication

CAS --.--.---- Circadian Alertness Simulator

CASA --.---- Civil Aviation Safety Authority (Australia)

CASR -------- Civil Aviation Safety Regulation

EASA--------- European Aviation Safety Agency

ETOPS --.---- Extended-Range Twin-Engine Operations

FAA ---------- Federal Aviation Administration

FAID --------- Fatigue Audit InterDyne

FAST --_------ Fatigue Avoidance Scheduling Tool

FRMS--------- Fatigue Risk Management System

GM------------ Guidance Material

HOS --------- Hours of Service

ICAO --------- International Civil Aviation Organization

IFA ---_--_---- International Federation of Airworthiness

MRO---------- Maintenance Repair and Overhaul

NPRM-------- Notice of Proposed Rulemaking

NTSB --.----- National Transportation Safety Board

PERCLOS---- Percentage of Eye Closure

SAFTE-------- Sleep Activity Fatigue and Task Effectiveness

SMS ---------- Safety Management System

UK --.------- United Kingdom 



\section{Fatigue Risk Management in Aviation Maintenance: Current Best Practices and Potential Future Countermeasures}

\section{INTRODUCTION}

Aviation maintenance personnel face a particular risk of fatigue due to night shift work, the potential for long and unregulated duty times, and the sleep disruption that can result from these working conditions (Hackworth, Holcomb, Banks, Schroeder, \& Johnson, 2007; Johnson, Mason, Hall, \& Watson, 2001; Johnson, 2008). Fatigue management in aviation maintenance has received increasing attention from international bodies, national aviation authorities, investigation agencies, airlines, and maintenance and repair organizations (MROs). The purpose of this discussion paper is to summarize the current state of fatigue risk management in aviation maintenance and to examine emerging approaches to the management of maintainer fatigue.

This report presents best practices for maintenance fatigue risk management, drawn from published sources and the experience of industry personnel. The information on industry practices was obtained from 50 individuals in aviation authorities, airlines, maintenance organizations, and the internal company documents they kindly provided.

\section{Fatigue Risk Management Principles}

In recent years, comprehensive fatigue risk management approaches have been adopted in aviation and road transport, supplementing, or in some cases replacing, older Hours of Service (HOS) approaches. Fatigue Risk Management Systems (FRMSs) have been promoted by the International Civil Aviation Organization (ICAO, 2008), the Federal Aviation Administration (2010), the European Aviation Safety Agency (EASA, 2009) Transport Canada (2007a), the Civil Aviation Safety Authority of Australia (CASA, 2009a), and agencies in the road and rail transport industries (Australian National Transport Commission, 2004; Gertler, Popkin, Nelson \& O’Neil, 2002). The FAA has defined FRMS as:

... a data driven and scientifically based process that allows for continuous monitoring and management of safety risks associated with fatigue-related error. It is part of a repeating performance improvement process. This process leads to continuous safety enhancements by identifying and addressing fatigue factors..." (FAA, 2010, p. 3).
Fatigue risk management is an application of the Safety Management System (SMS) model, through which hazards are identified and risk is managed with a comprehensive approach that extends beyond regulatory compliance (FAA, 2011a). FRMS can be integrated within an existing SMS or can be developed as a standalone system. The following principles can be found in the fatigue risk management literature:

- An FRMS requires a systemic approach, involving company policies, incident reporting and analysis systems, proactive risk assessment, and the other elements of a general safety management system (Australian National Transport Commission, 2004; FAA, 2010; Transport Canada, 2007a, 2007d).

- Effective fatigue risk management requires a partnership between the employer and the employee, as each can contribute uniquely to solutions (Dawson, 2000; Fletcher, 2007; Transport Canada, 2007b, 2007c).

- It is unrealistic to aim for "zero fatigue" in all cases. An appropriate objective for fatigue risk management is to ensure that risks are as low as reasonably practical (Stewart \& Holmes, 2008).

Most of the fatigue risk management approaches in industry have been designed for continuous-control tasks such as driving a vehicle or operating an aircraft. In such tasks, one of the major fatigue-related threats is an unwanted sleep episode, in the form of either an extended period of sleep or a microsleep. In maintenance, falling asleep at work is not the main hazard created by fatigue. Rather, a fatigued maintainer is at increased risk of maintenance errors due to impaired mental functioning. This distinction, while seemingly trivial, has important implications for fatigue risk management in aviation maintenance.

\section{Characteristics of Maintenance Work That can Assist With Fatigue Management}

Although maintenance personnel must contend with significant fatigue risks, some characteristics of aircraft maintenance provide opportunities to mitigate the hazards presented by fatigue.

First, maintenance tasks tend to be self-paced rather than externally paced, as defined by Broadbent (1953). Although much maintenance work is performed under 
time pressure, a maintainer conscious of impaired performance may be able to pause a task, trade speed for accuracy, or repeat a step as necessary.

Second, in some cases, there are opportunities to modify methods of task performance in maintenance. In many cases, task cards can be modified, and error-capturing barriers such as secondary inspections or operational/ functional checks can be introduced.

Third, maintenance organizations sometimes have flexibility to choose the time at which certain tasks are performed. In such cases it may be possible to schedule the most safety-critical tasks, or those most susceptible to fatigue, at times when fatigue will have the least impact.

Finally, maintainers are rarely required to travel across time zones while on duty. Consequently, jet lag and travel-related circadian rhythm disruption, which are major considerations for flight crew FRMS, are not usually relevant in the maintenance environment. The exception is when maintainers must travel to a remote work site to perform a task.

In summary, maintenance organizations face a unique set of fatigue-related challenges but also have access to a unique set of potential solutions. As a result, FRMS in maintenance can involve a wider range of countermeasures than comparable systems developed for flight crews or vehicle drivers.

\section{Employer and Employee Responsibilities}

The conditions that produce fatigue originate not only in the workplace but also in the employee's personal life (see Figure 1). Effective fatigue risk management requires a partnership with shared responsibility between the employee and the employer.

Workplace factors include working hours, staffing levels, and the availability of break periods. Personal factors leading to fatigue can include social and family commitments, commute time, second jobs, and medical conditions that may reduce the quality or quantity of sleep. The employee has a responsibility to ensure, as much as possible, that he or she is rested and "fit for duty" before reporting for work.

The not-for-profit International Federation of Airworthiness (IFA) has made the following statement in relation to the issue of maintainer fatigue: "Responsibility for the establishment and control of ... employees' duty hours and rest times does not solely rest with the company/ employer. Individuals have a responsibility to make use of the opportunities and facilities for rest periods provided. They are also responsible for planning and using their rest periods properly in order to minimize incurring fatigue" (Jauregui \& Hosey, 2007).

\section{Introducing Three Objectives of Fatigue Risk Management}

Fatigue risk management interventions can be characterized not only in terms of the activities that comprise the approach (such as hours of service limits and incident reporting systems) but also the intended objectives of these activities. An approach common to many risk management systems is a distinction between controls aimed at hazard prevention and controls directed at risk mitigation (International Organization for Standardization, 2009;

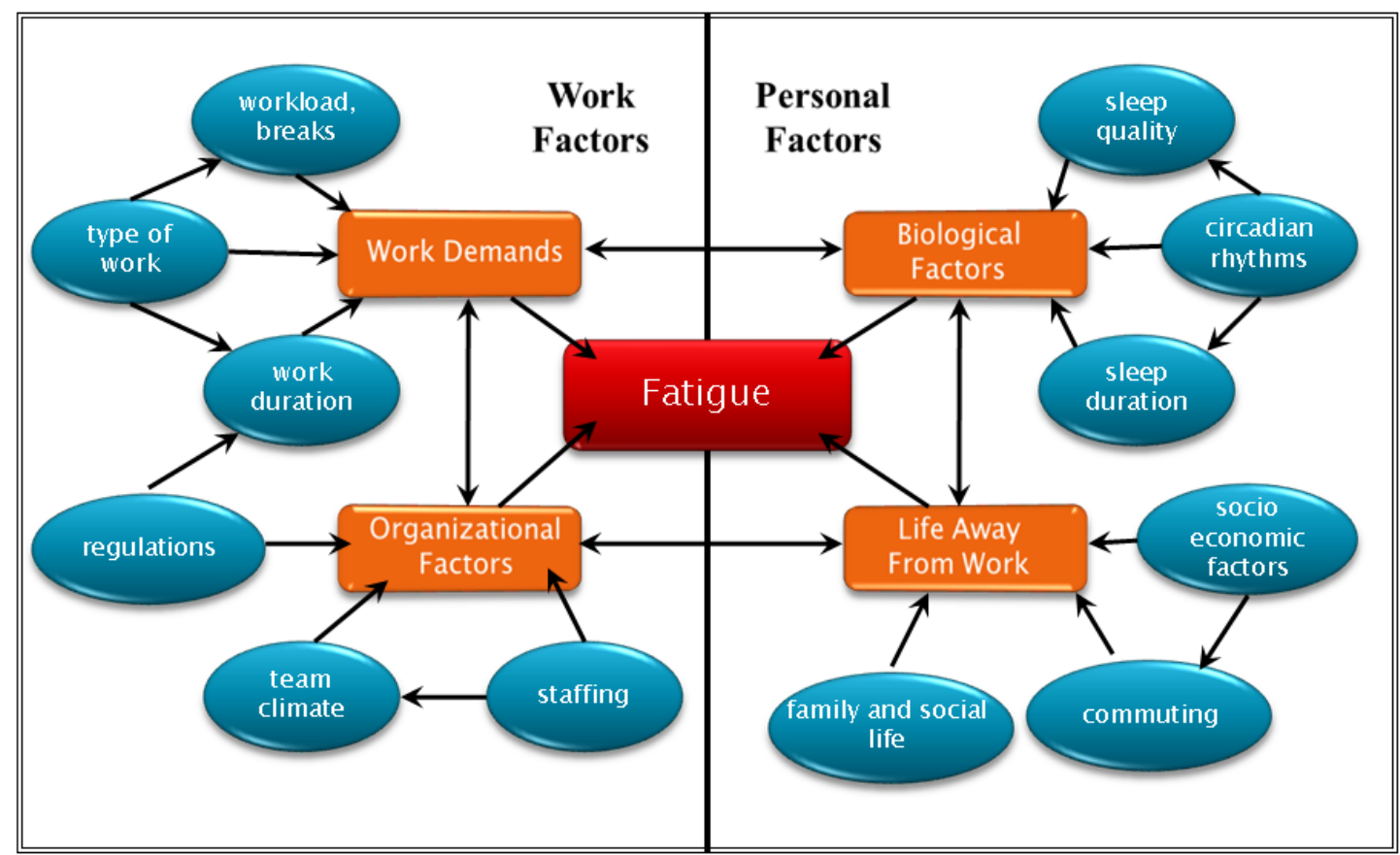

Figure 1. Workplace and personal factors contributing to employee fatigue. Adapted from the Australian National Transport Commission (2004). 
Reason \& Hobbs, 2003). Consistent with this distinction, three potential objectives of fatigue risk management can be identified:

1. Reduce fatigue. The first and most obvious objective of fatigue countermeasures is to reduce the level of fatigue experienced by personnel at work. This is the approach most commonly referred to when considering fatigue risk management. Hours of Service (HOS) limits and the re-design of shift schedules are examples of interventions intended to meet this objective.

2. Reduce or capture fatigue-related errors. The second class of interventions are designed to break the link between fatigue and performance decrements. This can be achieved by reducing the probability that a fatigued maintainer will make an error or capturing fatigue-related errors once they have occurred. Work breaks and additional task steps designed to capture errors are examples of such interventions.

3. Minimize the harm caused by errors. A final approach is to minimize, where possible, the operational consequences of fatigue-related errors. An example is a policy that prevents a fatigued maintainer from performing the same task on both engines of a twinengine aircraft. The policy is not intended to reduce fatigue or reduce the probability of error. Rather, it minimizes the operational impact of an error, should one occur.

As shown in Figure 2, each of three objectives can be considered as a layer of defenses in the "Swiss Cheese" model (Reason, 1990). Each objective will be considered in more detail in the following sections.

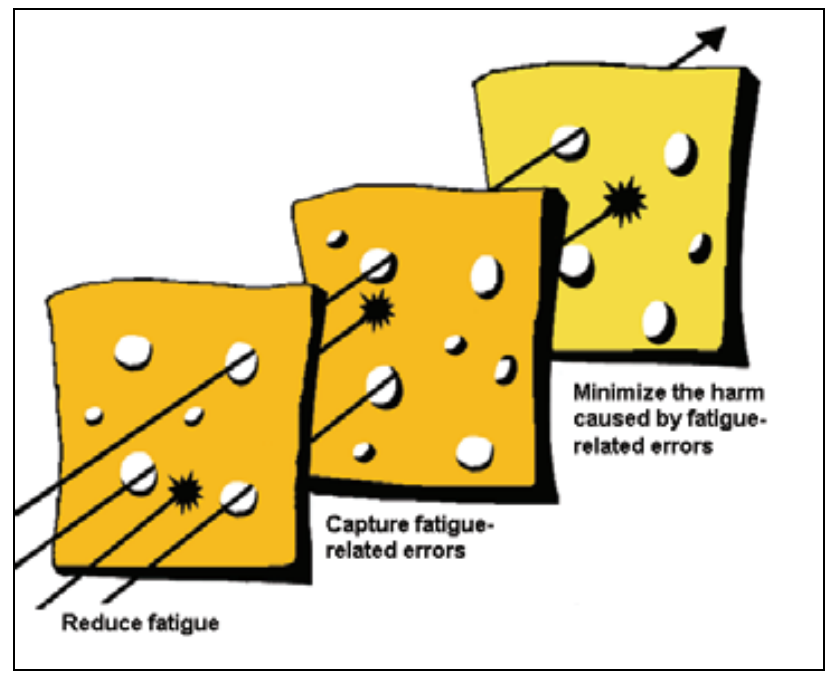

Figure 2. Three objectives of fatigue risk management interventions.

\section{OBJECTIVE 1 - REDUCE FATIGUE}

Fatigue reduction interventions are intended to minimize fatigue in the workplace, while recognizing that its complete elimination is not always practical. Interventions include HOS limits (whether voluntary or mandatory), scientific scheduling, napping strategies, education, excused absences, and in certain cases, medical treatment. These interventions are described in detail in the following sections.

\section{Hours of Service Limits Imposed by Aviation Authorities}

In the U.S., the only hours of service (HOS) limit currently applying to aviation maintenance is Title 14 of the Code of Federal Regulations (CFR) Part 121, $\$ 121.121 .377$. It requires that a person performing maintenance be relieved of duty for at least 24 hours in any seven consecutive days or the equivalent within a calendar month. In effect, a person could work up to 52 days straight, in a period of two consecutive months, and still be in compliance with the regulation (FAA, 2011b). The FAA regulation, however, only applies to personnel maintaining aircraft operated by part 121 air carriers. As part of its international assistance activities, the FAA formerly provided overseas regulators with model rest and duty limitations for maintenance personnel. These included a 12 -hour limit on HOS, extendable to 16 hours in the case of unscheduled maintenance (see Appendix A). An FAA work group is currently developing draft HOS guidelines for maintenance. It is uncertain whether the FAA will propose HOS regulations at some future time.

The New Zealand Civil Aviation Authority (2007) is one of the few regulatory bodies to specify duty limits for maintenance personnel. New Zealand Civil Aviation Rule Part 43.53 requires that before performing work, maintenance personnel must have had at least eight hours off duty in the preceding 24 hours and at least four periods of 24 consecutive hours of break in the preceding month.

The Civil Aviation Administration of China (CAAC) (2005) specifies a maximum duty time for aviation maintenance personnel of eight hours per day, with a maximum of 40 hours per week. Extended duty is permitted under special circumstances, up to a total of 11 hours per day. However, total monthly overtime is limited to 36 hours per month.

The European Aviation Safety Agency (EASA) and the United Kingdom Civil Aviation Authority (UK CAA) do not specify HOS limitations for maintenance personnel; however, the UK CAA commissioned Professor Simon Folkard (2003) to develop comprehensive guidelines for best practices. Five key items from Folkard's guidelines are: 
- There should be a 12-hour limit on shift duration

- No shift should be extended beyond 13 hours by overtime

- A break of at least 11 hours should occur between shifts

- There should be a work break every four hours

- A month's notice of work schedules should be provided

As Folkard (2003) notes, predictability in work schedules enables staff to plan their activities to ensure that they arrive at work well-rested. The Folkard guidelines can be found in full in Appendix B.

Folkard's guidelines have had a worldwide impact. They have been adopted by at least one regulatory agency (Civil Aviation Department, 2009), have been included in the UK CAA advisory document for part 145 operators (CAA, 2003), and in a guidance document for maintenance organizations released by ICAO (2003).

In Australia, CASA does not specify HOS limits for maintenance personnel. However, a new CASA regulation effective in June 2011 (CASA, 2009b), based on EASA part 145, makes it an offense for a maintenance organization to permit a maintainer who is significantly impaired by fatigue or a psychoactive substance to carry out maintenance on an airline aircraft. The regulation also requires organizations to ensure that schedules permit maintainers to take sufficient rest. The rules also prohibit organizations from requiring people to continue working if their capacity to carry out maintenance work has become significantly impaired (CASA, 2004). The Acceptable Means of Compliance (AMC) associated with CASR 145 notes that a FRMS is an acceptable means to comply with the intent of those parts of the regulation dealing with fatigue. CASA recommends that operators consider adopting Folkard's HOS guidelines as part of their fatigue risk management system (CASA, 2009b).

\section{Hours of Service Policies of Non-Government Agencies and Airlines}

The International Federation of Airworthiness has published non-binding recommendations for maintenance duty periods (Jauregui \& Hosey, 2007). (See Appendix C). In summary, the IFA recommendations specify that:

- No scheduled shift should exceed 12 hours

- No shift should be extended beyond 16 hours

- There should be no more than 72 hours scheduled duty in a seven-day period

- If 12-hour night shifts are scheduled, there should be no more than four in any seven-day period

In the absence of regulatory limits, several airlines and Maintenance Repair and Overhaul (MRO) organizations have introduced HOS limits for their maintenance personnel. Examples of HOS policies from several operators are given below:

- One airline limits planned shifts to 12 hours duration, with the possibility of extending to 13 hours. The weekly working hours are limited to 48 hours in total. (The maintenance fatigue policy of this airline can be found in full in Appendix D.)

- Another airline possesses a much more liberal HOS policy, permitting up to 20 hours of work attendance in a 24-hour period and up to 36 work hours, exclusive of lunch, in any two consecutive 24-hour days. Such work hours could produce significant levels of fatigue.

- An MRO reported that it had adopted the Folkard recommendations as its HOS policy, applying a limit of 12 hours, with the potential to extend to 13 hours with overtime.

Special circumstances, such as an aircraft on ground (AOG) at a remote station, can require extended duty times. In these situations, a team of maintenance personnel may need to travel significant distances across time zones and then work for an extended period to return the aircraft to service. Typically, the work will be of a highly technical nature, since it is assumed the aircraft is AOG because a flight-critical system is affected. In many cases, maintenance personnel are eager to undertake these tasks (often referred to as "field trips" or "away jobs") because significant overtime pay can be involved.

Several airlines have taken steps to minimize the impact of fatigue when maintenance personnel must travel to a remote location. Some airlines will send two crews for large jobs and provide hotel accommodation to allow crews to alternate rest periods. In other cases, restrictions similar to flight crew duty times are applied. One airline has a detailed policy for maintenance tasks requiring travel. This policy includes:

- A break of eight hours (including food and formal lodging) should be provided and used by individuals concerned

- When necessary, relief personnel should be dispatched for tasks with durations greater than 18 hours

- Where relief personnel are not feasible due to resource limitations or distance, then at least one additional individual should be allocated to the effort for the purpose of staggering total duty time more evenly among personnel

- Where possible, personnel selected for field trips should be at the start of their normal duty shift, as opposed to those at the end of their normal shift or day-off rotation

- If it is necessary to drive to and from a remote worksite, the fatiguing effects of driving should be taken into account when planning the task 
A potential risk with maximum HOS limits is that they become de facto standard working hours, rather than upper bounds on normal working hours. For example, the standard airline maintenance shift duration in Australia is 12 hours, at the upper limit of Folkard's recommendations.

\section{Scientific Scheduling Models}

In recent years, software modeling systems have been incorporated into many FRMS. Software models have advantages over HOS limits as they can take into account circadian variations in alertness, and sleep obtained, to produce an estimate of the fatigue level that may result from a particular shift pattern. When used as scheduling tools, software models have the advantage of offering greater flexibility than HOS limits. However, they can also be implemented in conjunction with hard limits.

Commonly used models include Fatigue Audit InterDyne (FAID), the Sleep Activity Fatigue and Task Effectiveness (SAFTE), the related Fatigue Avoidance Scheduling Tool (FAST), and the Circadian Alertness Simulator (CAS) model, which has been used extensively in the railroad industry. As an example, the FAID system requires the input of the employee's work and break times over a seven-day period. The system then produces fatigue scores ranging from 0 to 140 , which express the level of fatigue likely to be experienced by the person. The developers of FAID consider scores less than 80 to be generally safe for the transport industry, but scores above 80 may indicate an unsafe condition - depending upon the nature of the work being performed (Dawson \& Fletcher, 2001; Fletcher \& Dawson, 2001). Recent research by the Federal Railroad Administration, however, has suggested that FAID scores as low as 60 can represent an unacceptable accident risk (Tabak \& Raslear, 2010).

In the aviation industry, fatigue models have been applied mainly to flight crew scheduling. One airline, however, reported using FAID to evaluate maintenance work schedules for line and heavy maintenance. The airline continues to use FAID to assist with manpower planning in heavy maintenance. FAID has also been used to design maintenance schedules by an organization that maintains airways facilities such as instrument landing systems, radar and en-route navigation aids.

Software modeling can be a useful tool as part of a comprehensive FRMS but must be used cautiously, with an awareness of the capabilities and limitations of computerized models (Independent Transport Safety Regulator, 2010). For a comprehensive review of fatigue modeling systems, see Mallis, Mejdal, Nguyen, and Dinges (2004).

\section{Napping Strategies}

Naps can be helpful either as a preventative measure, as when taken before reporting for a night of shiftwork or as a way of improving alertness during a night shift (Ficca, Axelsson, Mollicone, Muto, \& Vitiello, 2010). Controlled studies have shown that even a brief sleep episode can result in performance improvements. For instance, Purnell, Feyer and Herbison (2002) found that the vigilance performance of aircraft maintenance personnel on the first of two consecutive 12-hour night shifts (1900 - 0700) was improved by a 20 -minute nap taken at around $3 \mathrm{a} . \mathrm{m}$. For reasons that are unclear, no improvement was found on the second of the two night shifts. Other studies have found that brief controlled sleeps of less than 40-minute duration can significantly increase the alertness of airline pilots, resulting in fewer lapses and reduced response time to stimuli (Rosekind et al., 1994). Similar benefits have been found for air traffic controllers (Della Rocco, Comperatore, Caldwell, \& Cruz, 2000) and truck drivers (Macchi, Boulos, Ranney, Simmons, \& Campbell, 2002). Napping as a fatigue countermeasure in maintenance may face resistance from airlines and regulators. However, informal napping arrangements are known to already occur during maintenance nightshifts as a countermeasure to extreme fatigue (Rhodes, Lounsbury, Steele, \& Ladha, 2003). One airline reported that it provides beds to let maintenance workers nap at the end of their shifts before driving home.

A potential hazard associated with napping is that sleep periods lasting more than about 40 minutes may produce "sleep inertia," a feeling of grogginess and disorientation that may persist for some time after awakening (Van Dongen et al., 2001; Wertz, Rhonda, Czeisler, \& Wright, 2006).

\section{Training and Educational Material}

The provision of educational material is one of the few steps the organization can take to help employees reduce fatigue arising from personal lifestyle factors. ${ }^{1}$

The FAA provides maintenance personnel with extensive educational material on fatigue, including a computer-based fatigue countermeasure workshop, a newsletter, video material, and posters. This material can be accessed at: https://hfskyway.faa.gov or the shortcut www.mxfatigue.com.

The maintenance guidance material for EASA Part 145 (2003) includes fatigue as one of the topics that should be covered in human factors training for employees of Part 145 maintenance organizations. EASA Part 66 also specifies that fatigue awareness should be covered

\footnotetext{
${ }^{1}$ Some aspects of education deal with recognizing and responding to fatigue; however, for simplicity, education is included here as a measure intended to reduce or eliminate fatigue.
} 
in initial training of maintenance personnel. The new CASA regulation, CASR 145, mirrors the requirements of the EASA regulations (CASA, 2009b). The UK CAA has produced two Civil Aviation Publications (CAPs) on maintenance human factors designed to meet the EASA requirements. CAP 715 (CAA, 2002) is a companion document to EASA Part 66 and provides educational material on sleep, fatigue, and shiftwork suitable for personnel obtaining their initial maintenance certification. The related CAP 716 (CAA, 2003) supplements EASA Part 145 and provides extensive information on fatigue targeted at the needs of Part 145 operators and personnel. The UK CAA has also issued a leaflet for maintenance personnel, reminding them of the dangers of impaired performance due to tiredness and fatigue (CAA, 2009).

Transport Canada has released educational material as part of its fatigue risk management system toolbox, including two documents providing awareness material, "An Introduction to Managing Fatigue" and "Fatigue Management Strategies for Employees." The first document gives a brief overview of the topic, while the second contains detail on fatigue, fatigue management strategies, as well as information on nutrition, drugs, alcohol, napping, exercise, and well-being (Transport Canada, 2007b, 2007c).

Who should receive training? While it is clear that AMTs and inspectors require information on fatigue and its effects, other work categories should not be overlooked. Managers, supervisors, and maintenance planners have an important role in managing the risk of fatigue. It is critical that they have the knowledge to enable them to schedule tasks in order to reduce the impact of fatigue.

The Acceptable Means of Compliance (AMC) to EASA Part 145 (EASA, 2003) indicates that the following maintenance personnel should receive human factors training, which will include coverage of fatigue.

- Post-holders, managers, supervisors

- Certifying staff, technicians, and mechanics

- Technical support personnel such as planners, engineers, and technical record staff

- Quality control/assurance staff

- Specialized services staff

- Human factors staff and human factors trainers

- Stores and purchasing department staff

- Ground equipment operators

- Contract staff in the above categories

The families of shift workers should also receive information on fatigue issues and steps they can take to help their shift worker obtain sleep. The document, "Introduction to Managing Fatigue," published by Transport Canada (2007b), includes a section on social and family life. One airline reported that it provided its maintenance staff with an informational booklet describing ways to balance family life and work, and advice on "daytime sleeping rules” to help family members understand (Klein, 1997).

\section{Excused Absences}

Some FRMS enable employees to take unplanned leave if they believe their level of fatigue would prevent them from performing their duties (Cook, 2008). At least one airline permits a fatigued flight crew member to call the safety department to request an excused absence. The safety department then contacts the employee's supervisor, in order to insulate the employee from potentially negative consequences.

While sick leave is a generally accepted aspect of personnel management, "fatigue leave" may be less readily accepted. Organizations need to weigh the potential disruption caused by an unplanned absence with the potential harm that could result when an employee reports for duty impaired. A reasonable manager is likely to be sympathetic when the fatigue is a result of a family emergency but may be reluctant to approve an unplanned absence if the fatigue is seen to be self-induced by lifestyle choices or leisure activities.

Call-in systems rely on self-identification of fatigue, yet it is well-established that individuals are not good judges of their own level of fatigue. Additionally, although it may appear that employees could abuse the system, in the case of hourly workers whose income depends upon work attendance, it is more likely that the system would be underused rather than overused.

\section{Medical Treatment}

In some cases fatigue will be a consequence of an underlying medical condition, such as insomnia or sleep apnea (Kryger, Roth \& Dement, 2005). In these situations, medical attention will be required to address the root cause of the problem. A comprehensive FRMS must include measures to ensure that at-risk employees receive appropriate medical treatment.

\section{OBJECTIVE 2-REDUCE OR CAPTURE FATIGUE-RELATED ERRORS}

Despite efforts to ensure that employees are well-rested and alert when they report for duty, it is not possible to completely eliminate fatigue from the workplace. Therefore, it is appropriate to have a second line of defense with the objective of reducing the probability of error among fatigued workers. The plain-language slogan of this approach could be, "We know that people are going to be fatigued. How can we manage the risk when a fatigued maintainer is at work?" 
These interventions can involve two approaches: measures directed towards individuals, and measures directed towards tasks.

\section{Measures Directed Towards Individuals}

This section covers several approaches that help fatigued individuals to recognize their level of fatigue and to take steps to obtain temporary relief.

Self-assessment. The most obvious way to detect fatigue is self-assessment by the employee. Several quick assessment guides are available to assist with this judgment, although they should be used with caution as individuals are not always accurate judges of their own level of fatigue (Dinges, Mallis, Maislin, \& Powell, 1998).

An airline reported that it issues all personnel, including those in maintenance, with a Fatigue Likelihood Assessment card that contains three questions: (a) sleep in prior 24 hours, (b) sleep in prior 48 hours, and (c) hours awake since last sleep period. Depending on the answers to these questions, the card recommends one of three actions. In cases of low fatigue, the recommendation is "Keep an eye on yourself." At moderate levels of fatigue, the recommendation is "Look out for each other." At the highest fatigue level, the card advises "Go back to bed."

A European operator utilizes a fatigue risk assessment system for maintenance personnel that assigns a rating to a planned task according to the recent work history of the employee and the nature of the task to be performed. However, the scale does not consider sleep obtained in the last sleep period, or time of day, the two most important factors determining sleepiness. The scale can be found in Appendix E.

Subjective fatigue ratings used in research studies may be adaptable for use in maintenance environments. The Stanford Sleepiness Scale is a seven-point scale with anchors ranging from "Feeling active and vital, alert, wide awake" to "Almost in a reverie, sleep onset soon, lost struggle to remain awake." The scale is used extensively in research (Hoddes, Zarcone, Smythe, \& Dement, 1973) and its wording may be more appropriate to research laboratories than hangars. A second widely-used fatigue scale is the Karolinska index, which enables alertness to be rated on a nine-point scale, using plain language anchor points ranging from "Very alert" to "Very sleepy, great effort to keep awake" (Akerstedt \& Gillberg, 1990). The Stanford and Karolinska scales can be found in Appendix F.

Fatigue detection technology. Several technologies offer the possibility of detecting a dangerous level of fatigue at the start of a shift or continuously throughout task performance. Psychomotor performance tests have been used widely in research studies and have been shown to be effective indicators of a person's vigilance performance when fatigued. The tests are usually installed on a handheld device or even a smartphone and typically measure the person's speed of response to a stimulus (Dinges \& Powell, 1985; Thorne et al., 2005). The recent widespread availability of smartphones and personal electronic devices mean that personal fatigue monitoring may soon become a feasible method to evaluate the level of alertness among shiftworkers. Figure 3 shows a psychomotor vigilance test installed on a handheld device. Performance testing has been used to detect fatigue in the mining industry and has been promoted as a means of establishing fitness for duty in maintenance (Dupont \& Dupont, 2010). Voice analysis also shows promise as a method to detect fatigue in operational personnel, particularly in settings where verbal communication occurs via radio or telephone (Greeley et al., 2007).

A range of alertness monitoring systems have been developed for the road transport industry, and several models of vehicles now come equipped with systems designed to detect drowsy drivers. Fatigue may be detected

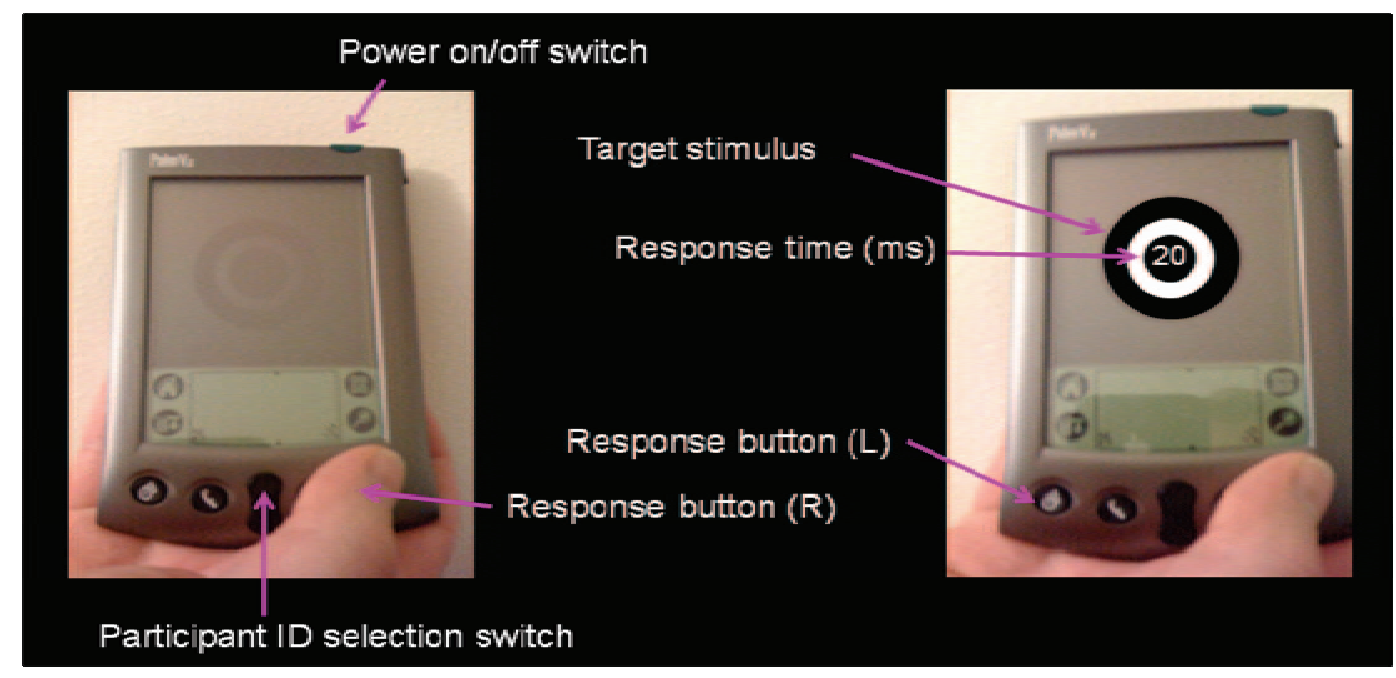

Figure 3. A Psychomotor Vigilance test installed on a handheld device. 
by monitoring eye movements, blink rate, and performance measures such as steering accuracy (Williamson \& Chamberlain, 2005). One of the best known fatigue detection systems (PERCLOS) monitors eye closures to assess drowsiness (Dinges et al., 1998).

While acknowledging that alertness monitoring systems are not likely to be adopted in maintenance in the near future, it is conceivable that they may eventually play a part in an overall FRMS.

Breaks. Research shows that a period of exercise, such as a brief walk, can increase alertness and temporarily reverse the impact of fatigue on some psychomotor tasks (Bonnet, 2005; Bonnet \& Arand, 1998; Wilkinson, 1965). A maintenance technician experiencing extreme fatigue may be able to call "time out" and down tools for a moment, or perform a part of a task that requires physical activity, such as walking to a storeroom. However, breaks provide only temporary relief lasting a matter of minutes and are not feasible strategies for managing fatigue over long periods of time.

Workplace environment. Certain aspects of the work environment can either exacerbate or mask the effects of fatigue. In some cases, improvements to the work environment may help maintainers cope with fatigue.

There is evidence that bright light can increase attentiveness and reduce errors among otherwise fatigued individuals (Cajochen, 2007; Caldwell et al., 2009; Campbell \& Dawson, 1990; Dawson, Encel, \& Lushington, 1995; Moore-Ede, 1993). These findings are a reminder that tasks performed in a dark environment, such as fluorescent penetrant inspections, will be particularly challenging for a fatigued individual. Exposure to fresh air or cool, dry air may also provide relief from fatigue, although the benefit is temporary and may be slight (Bonnet, 2005; Moore-Ede, 1993). Posture may also have an impact of fatigue susceptibility. An activity that is carried out while standing or walking is less likely to be affected by fatigue than an activity performed in a prone or seated position (Bonnet, 2005). One European operator does not allow maintenance staff to work extended hours if the work involves confined spaces, heights, extreme temperatures, or other physically demanding environments.

Stimulants. Caffeine is one of the most widely used stimulants, and if used carefully and in moderation, can be part of an overall fatigue risk management strategy in maintenance. Caffeine has a half-life in the body of around five hours, and shiftworkers should be careful to avoid caffeine in the hours leading up to sleep. An exception is where caffeine is intentionally taken immediately prior to a brief nap. The alertness-enhancing effects of caffeine do not occur until approximately 30 minutes after the caffeine has been consumed, leaving a brief window in which a useful nap may be taken. Caffeine, followed im- mediately by a brief nap, has been shown to significantly reduce fatigue during the two hours following the nap (Reyner \& Horne, 1997). When caffeine is used as a fatigue countermeasure, it is generally recommended that the person avoids the routine consumption of caffeinated drinks, as caffeine is less effective as an alerting agent for people who have developed caffeine dependence (Mitler \& O’Malley, 2007).

Alertness-enhancing medications other than caffeine are used to reverse the effects of sleep loss for some military missions (Caldwell et al., 2009). There have been suggestions that such substances may have potential as fatigue countermeasures in aviation maintenance. Modafinil (chemical name) is a prescription wakefulnesspromoting drug that has been used to treat excessive sleepiness caused by medical conditions and "shiftwork sleep disorder" (National Center for Biotechnology Information, 2008). In a laboratory simulation of night shift, in which participants performed a variety of tasks between 23:00 and 07:00 four nights in a row, Modafinil was shown to improve cognitive performance (Walsh, Randazzo, Stone \& Schweitzer, 2004). There are ethical and medical questions associated with the use of such medications for shiftworkers, including potential interactions with other medications and possible long-term effects. Akerstedt and Wright (2009) note that "Treating healthy shiftworkers with pharmaceutical products is questionable and the risks associated with the treatment need to be weighed against the risks associated with no treatment and/or ... alternative treatments" (p.265). In conclusion, the suitability of a prescription medicine is a matter for the employee and his or her medical provider, and it is unlikely that alertness-enhancing drugs will be an accepted organizational-level part of a FRMS in the near future.

\section{Measures Directed Towards At-Risk Tasks}

In addition to managing fatigue at the level of the individual, it is also possible to break the link between fatigue and error by changing aspects of the task assigned to the maintainer. Because much of the worldwide work on fatigue risk management has been directed at pilots or vehicle operators, task-based approaches have received relatively little attention. Task-based approaches are based on the idea that maintenance tasks vary along a continuum, from tasks that are highly susceptible to fatigue, to those that are less susceptible. This approach is based upon the probability that an error will occur on a task, not necessarily the severity of the consequences.

Task-based approaches to harm minimization can involve two complimentary strategies: changing when the task is performed, and changing how it is performed. 
Task scheduling interventions. Even if the steps involved in a maintenance procedure cannot be modified, it may still be possible to reduce the susceptibility of a task to fatigue through careful task scheduling.

The following types of tasks are likely to be most susceptible to fatigue-related errors:

- Tasks that are monotonous or boring

- Inspection tasks

- Familiar tasks and those that can be performed "automatically" with minimal need for attention

- Tasks that rely on prospective memory (memory for intentions)

- Task requiring intense, continuous concentration

- Tasks performed in a darkened environment, such as specialized inspections

- Tasks where incorrect performance is not immediately obvious (Hobbs, Williamson \& Van Dongen, 2010; Reason \& Hobbs, 2003; Rhodes et al., 2003)

An in-depth study of the fatigue susceptibility of aviation maintenance tasks was carried out for Transport Canada (Rhodes et al., 2003). The researchers found that tasks involving attention, visual perception, auditory perception, working memory, and information processing were at greatest risk of fatigue-related degradation. The authors recommended that the following types of maintenance tasks be avoided during times at which fatigue effects are known to occur:

- Inter-Trade Communications

- In-depth supervision

- Training

- Troubleshooting

- Testing

- Calibration

- Inspection

- Job planning

- Documenting of work

Most maintenance organizations do not appear to take the fatigue susceptibility of a procedure into account when scheduling tasks. In some cases, individual maintainers have informal norms concerning the time of day at which tasks are performed. For example, when airline maintenance technicians have discretion about the timing of their tasks, they sometimes choose to perform the most challenging tasks at the beginning of their shift, leaving less complex tasks until the end of the shift, when they expect to be less alert (Parliament of Australia, 2000).

In most large organizations, AMTs have limited control over the timing of tasks throughout their shift, yet crew leads, foremen, or planning personnel may have some influence on the time of day at which certain tasks are performed. It is critical, therefore, that such personnel have an awareness of the effects of fatigue on human performance.

Several regulatory authorities have acknowledged that appropriate production planning can help to reduce the impact of fatigue on work quality. EASA regulations state that "The planning of maintenance tasks, and the organizing of shifts, shall take into account human performance limitations" (EASA Part 145. Section 145.A.47 [b]). CASA's regulation 145 includes similar language (CASA, 2004). The UK CAA advises maintenance personnel to plan their work so as to avoid complex tasks during the window of circadian low (CAA, 2002).

Fatigue-proofing of task procedures. In some cases, it is possible to modify task procedures to reduce the task's susceptibility to fatigue-related errors or to detect the presence of an error. Such task-based interventions are sometimes referred to as "fatigue proofing." Transport Canada, one of the few organizations to propose taskbased approaches to risk mitigation in maintenance, recommends the following fatigue-proofing strategies for tasks that may be susceptible to fatigue (Transport Canada, 2007a):

- Close supervision

- Working in pairs or teams depending on the task

- Task rotation

- Checklists

- Support for new personnel by experienced personnel

- Communication/briefings at shift hand-over

ICAO has also made reference to task-based fatigue countermeasures. ICAO recommends breaking down lengthy repetitive tasks into smaller tasks, with breaks in between, and making appropriate additional checks on work performed by personnel on night shift (ICAO, 2003).

Tasks that are especially susceptible to fatigue or that have a history of repetitive error may require specific countermeasures to detect the presence of error. These defenses can include independent inspections, operational or functional checks, and formalized self-checks. Rhodes et al. (2003) recommended that maintenance tasks performed during the window of circadian low (between 0300 and 0600 ) should be checked by rested personnel.

Operational and functional checks, such as engine runs or pressure checks, are among the most useful means of uncovering maintenance errors on systems that involve complex assemblies. A fatal commercial accident involving a Beech 1900 occurred after maintenance personnel on the night shift made an error when rigging the elevator control system. The task card for the procedure contained no requirement for measurements of elevator deflection at the completion of the task, a step that may have detected the earlier error (NTSB, 2004). As a result 
Table 1. Maintenance tasks can be assessed in terms of their safety criticality and their susceptibility to fatigue.

\begin{tabular}{|c|l|l|}
\hline $\begin{array}{c}\text { SUSCEPTIBILITY OF } \\
\text { TASK TO FATIGUE }\end{array}$ & \multicolumn{1}{|c|}{ CRITICALITY TO SAFETY OF FLIGHT } \\
\hline Highly susceptible & $\begin{array}{l}\text { Highly critical } \\
\text { Example: Dye penetrant inspection } \\
\text { for fatigue cracks on engine } \\
\text { component. (Task requires intense } \\
\text { concentration in dark room.) }\end{array}$ & $\begin{array}{l}{ }^{I} \\
\text { Example: Checking expiry dates on } \\
\text { life jackets. (Monotonous task that } \\
\text { requires mechanic to lie on floor to } \\
\text { get access under seats.) }\end{array}$ \\
\hline Less susceptible & $\begin{array}{l}\text { Example: Returning work stands to } \\
\text { storage areas. (Involves non-flight } \\
\text { critical equipment, mild physical } \\
\text { activity and variety.) }\end{array}$ \\
\hline
\end{tabular}

${ }^{1}$ It is acknowledged that all maintenance tasks have the potential to affect flight safety.

of its investigation, the NTSB recommended that the FAA require post-maintenance functional checks after all maintenance on critical flight systems or components. Such checks would be particularly critical in the case of maintenance performed by fatigued personnel.

Of course, even when it is possible to modify a task or change the time at which it is performed, no task can ever be made completely "fatigue proof." Nevertheless, task-based strategies can serve as part of an overall FRMS.

\section{OBJECTIVE 3-MINIMIZING THE HARM CAUSED BY FATIGUE-RELATED ERRORS}

After efforts have been made to reduce fatigue and to prevent or capture fatigue-related errors, a final line of defense is to minimize the harm caused by these errors. Although all maintenance tasks can affect flight safety, tasks vary along a continuum from the most safety-critical to the least critical. Harm minimization differs from the interventions described in the preceding sections, as the focus is on the severity of the error's consequences, rather than the probability of error. The plain-language slogan of this approach could be: "Despite our best efforts, fatigue-related errors will happen from time to time. How can we make sure these errors do not have serious consequences?"

Harm minimization in the context of maintenance fatigue involves keeping the most safety-critical tasks out of the hands of the most fatigued people. An example would be task scheduling that avoids assigning work on flight control systems to individuals during their circadian low point, instead assigns them less-critical tasks. This approach does not prevent maintainers from making a fatigue-related error on whatever task they are assigned but reduces the likely consequences of that error.
For example, if an overnight task involves a disassembly stage, followed by an assembly stage, it may be feasible to schedule the disassembly for the time of maximum fatigue and the assembly for a time at which fatigue is less likely. This arrangement is based on the assumption that an error during assembly is likely to be more serious than an error during disassembly.

As has been noted, the harm minimization approach takes the criticality of the task into account. This contrasts with the task-based approaches that are based on the task's susceptibility to fatigue. Table 1 illustrates how the two approaches can be combined and shows how tasks can be categorized according to criticality and fatigue susceptibility.

The harm minimization approach may involve a formalized policy of progressive restrictions on work responsibilities (Dawson, 2000). This involves limiting the involvement of the individual in critical tasks as their level of fatigue increases. The progressive restriction approach has been recommended by the International Federation of Airworthiness. The IFA proposes that the certification and inspection authority of maintenance personnel should be limited when they have been on duty for longer than 12 hours (Jauregui \& Hosey, 2005). The text can be found in Appendix G.

One operator has introduced a system that imposes progressively more severe restrictions on certifying technicians as fatigue risk increases. A technician is judged to be at "medium" risk of fatigue as the shift passed beyond 12 hours (if a dayshift), or eight hours (if a nightshift), or when more than 48 hours have been worked in a seven-day period. These staff members are prohibited from carrying out secondary independent inspections and detailed inspections, and they must have no involvement with structurally significant items. They are also not 


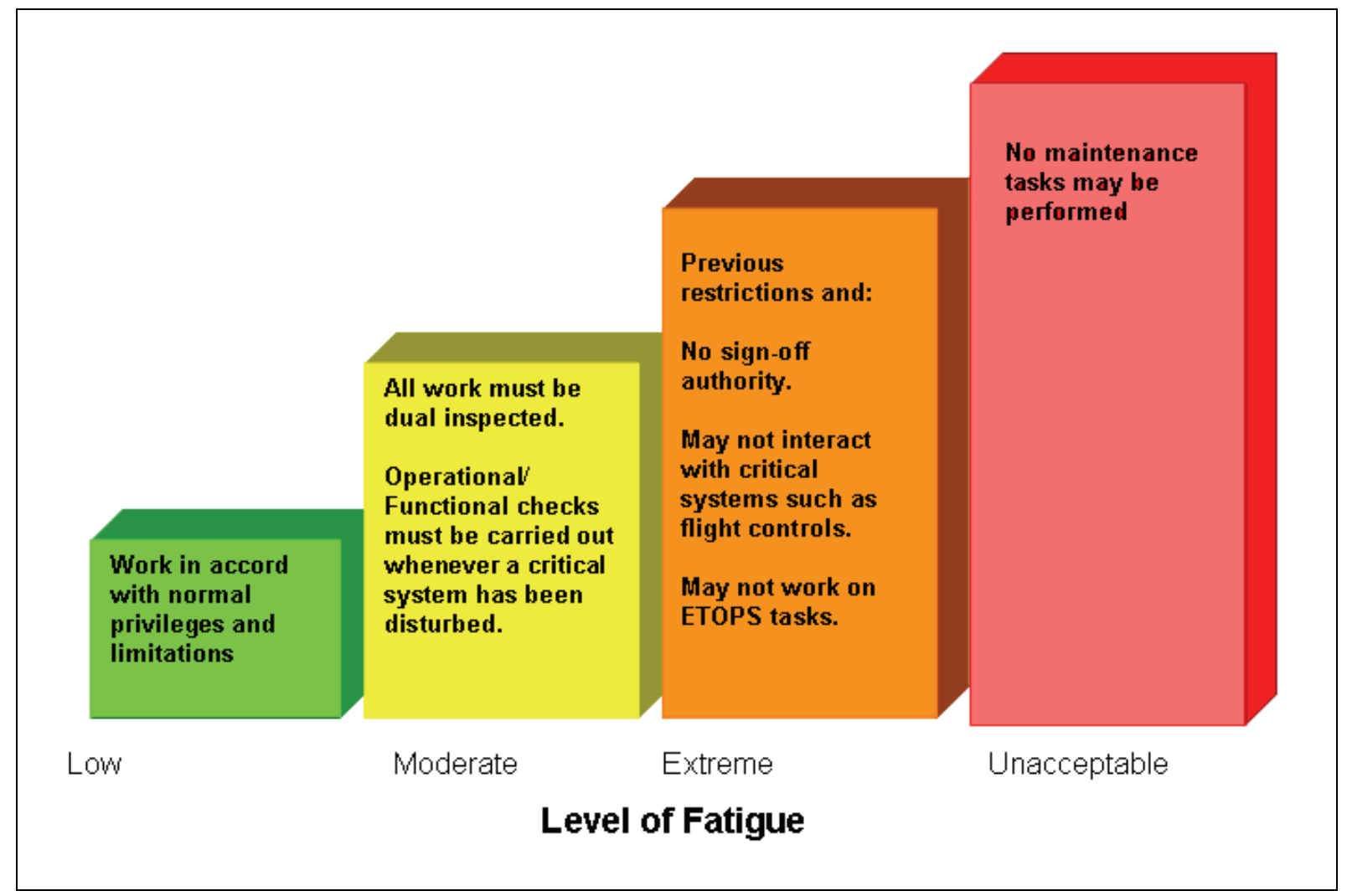

Figure 4. Example of the progressive restriction of work responsibilities as fatigue risk increases.

permitted to work on aircraft used for extended-range twin-engine operations (ETOPS). Technicians are judged to be at "high" risk of fatigue when a day shift is extended beyond 14 hours (beyond 12 hours for a nightshift), or when they have worked more than 60 hours in a seven-day period. In addition to the above limitations, personnel at high risk of fatigue are not allowed to perform any critical tasks (including the performance or certification of Airworthiness Directives), are not permitted to be in charge of engine runs, must not be responsible for functional or operational checks on critical systems, and are not permitted to taxi aircraft. "Unacceptable" fatigue risk is judged to commence after 16 hours of duty (if the duty period started as dayshift) or 14 hours (if the duty period started as a nightshift) or after working more than 72 hours in a seven-day period. A staff member with an "unacceptable" fatigue risk is not considered safe to perform any work activities.

An illustration of the progressive restriction approach in maintenance is shown in Figure 4. When such a policy is introduced, care must be taken to avoid unwanted consequences. In particular, the removal of responsibilities from personnel judged to be at risk of fatigue could increase the workload of the remaining staff.

\section{SUMMARY AND CONCLUSIONS}

Fatigue is a particular challenge in aviation maintenance due to the need to perform tasks at night and the potential for long duty days. Many maintenance tasks, especially those involving intense visual attention, communication, or a heavy reliance on memory, are particularly susceptible to the effects of fatigue. However, maintenance also presents unique opportunities for fatigue risk management. In contrast to other sectors of the transport industry, maintenance organizations may have opportunities to alter the timing of tasks, may be able to consider an individual's level of fatigue when assigning tasks, and may be able to modify task procedures to reduce the impact of fatigue. This report has presented fatigue countermeasures ranging from initiatives that are already in place at maintenance operations to countermeasures (such as fatigue detection technology) that may have potential for future implementation.

The trend towards implementing formal fatigue riskmanagement systems in transport has been slow to reach aviation maintenance. An overall approach to fatigue risk management in maintenance can include interventions directed at three objectives: reducing fatigue, reducing 
Table 2. Mappings between fatigue interventions and fatigue risk-management objectives.

\begin{tabular}{|c|c|c|c|}
\hline & 1. Reducing fatigue & $\begin{array}{l}\text { 2. Reduce or } \\
\text { capture fatigue- } \\
\text { related errors }\end{array}$ & $\begin{array}{l}\text { 3. Minimize the harm } \\
\text { caused by fatigue- } \\
\text { related errors }\end{array}$ \\
\hline Hours of service (HOS) limits & $\mathrm{X}$ & & \\
\hline Scientific scheduling & $\mathrm{X}$ & & \\
\hline Napping strategies & $\mathrm{X}$ & & \\
\hline $\begin{array}{l}\text { Training and education for AMTs } \\
\text { and inspectors }\end{array}$ & $\mathrm{X}$ & $\mathrm{X}$ & \\
\hline $\begin{array}{l}\text { Training and education for } \\
\text { supervisors and planning staff }\end{array}$ & $\mathrm{X}$ & $\mathrm{X}$ & $\mathrm{X}$ \\
\hline Excused absences & & $\mathrm{X}$ & \\
\hline $\begin{array}{l}\text { Medical treatment for sleep } \\
\text { disorders }\end{array}$ & $\mathrm{X}$ & & \\
\hline Self-assessment & & $\mathrm{X}$ & \\
\hline Fatigue detection technology & $\mathrm{X}$ & $\mathrm{X}$ & \\
\hline Work breaks & $\mathrm{X}$ & $\mathrm{X}$ & \\
\hline Work environment & & $\mathrm{X}$ & \\
\hline Careful use of caffeine & $\mathrm{X}$ & $\mathrm{X}$ & \\
\hline Fatigue-proofing of task procedures & & $\mathrm{X}$ & $\mathrm{X}$ \\
\hline Task scheduling interventions & & $\mathrm{X}$ & $\mathrm{X}$ \\
\hline $\begin{array}{l}\text { Progressive restrictions of work } \\
\text { responsibilities }\end{array}$ & & $\mathrm{X}$ & $\mathrm{X}$ \\
\hline
\end{tabular}

or capturing fatigue-related errors, and minimizing the harm caused by fatigue-related errors. As shown in Table 2 , most fatigue countermeasures can address more than one of these objectives. Because the FRMS approach was originally developed for pilots and vehicle drivers, most existing FRMS focus on Objective 1- the reduction of fatigue. However, Objectives 2 and 3 deserve special attention in maintenance operations.

In some cases, HOS limits and software modeling of work schedules have been seen as competing approaches, yet the two approaches can be implemented together. HOS limits such as those proposed by Folkard (2003) can set the outer bounds of duty times, while software modeling can be used to design schedules within these bounds.

Figure 5 illustrates the elements of current, best-practice fatigue risk management systems for maintenance. We consider that HOS limits should be a central part of any FRMS. In the absence of national HOS regulations, companies can develop their own policies. In addition to HOS limits, an FRMS for maintenance will include a range of interventions addressing the task, the work environment, and the fitness for duty of personnel. In addition to the elements discussed in this report, an FRMS should include organizational-level elements such as company policies, reporting and incident analysis systems, risk assessment, and the periodic evaluation and improvement of the system.

Maintenance planners and scheduling personnel are in a key position to influence fatigue risk management. Although they comprise a relatively small percentage of the overall maintenance workforce, the decisions they make concerning task planning and assignment can either minimize or exacerbate the impact of fatigue on task performance.

Whatever approach to fatigue risk management is applied, commitment from all levels of the organization is essential. Upper management have a responsibility to state a clear policy on fatigue, including how fatiguerelated incidents will be dealt with under a just culture 


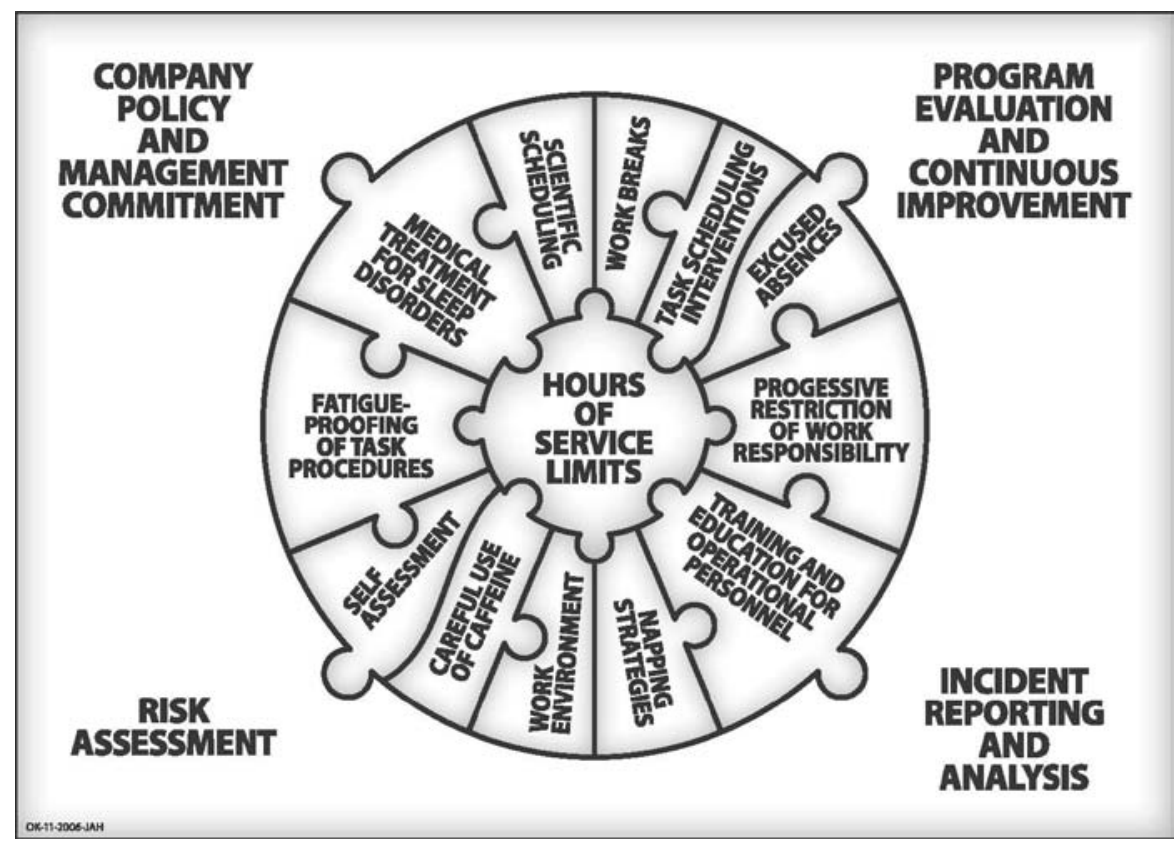

Figure 5. Elements of a fatigue risk-management system for maintenance.

policy. Supervisors and middle-level managers have a responsibility to ensure that the fatigue risk-management policy is applied in day-to-day operations. Supervisors, crew leads, and planners must ensure that fatigue and circadian factors are considered in task assignment and planning. Finally, individual aviation maintenance technicians and inspectors are ultimately responsible for the quality of their work. They must have a good understanding of fatigue and its effects, must strive to arrive for duty well-rested, and must have access to strategies to deal with workplace fatigue when it arises.

\section{REFERENCES}

Akerstedt, T., \& Gillberg, M. (1990). Subjective and objective sleepiness in the active individual. International Journal of Neuroscience, 52, 29-37.

Akerstedt, T., \& Wright, K. (2009). Sleep loss and fatigue in shift work and shift work disorder. Sleep Medicine Clinics, 4, 257-271.

Australian National Transport Commission (2004). Fatigue management within the rail industry: review of regulatory approach. Melbourne, Australia.

Broadbent, D. (1953). Noise, paced performance and vigilance tasks. British Journal of Psychology, 44, 295-303.
Bonnet, M. (2005). Acute sleep deprivation. In M. Kryger, T. Roth, \& W. Dement (Eds.), Principles and practice of sleep medicine (pp. 51-66). Philadelphia, PA: Elsevier.

Bonnet, M., \& Arand, D. (1998). Sleepiness as measured by the MSLT varies as a function of preceding activity. Sleep, 21, 477-483.

Cajochen, C. (2007). Alerting effects of light. Sleep Medicine Reviews, 11, 453-644.

Caldwell, J.A., Mallis, M., Caldwell, J.L., Paul, M., Miller, J., \& Neri, D. (2009). Fatigue countermeasures in aviation. Aviation Space and Environmental Medicine, 80, 29-59.

Campbell, S., \& Dawson, D. (1990). Enhancement of nighttime alertness and performance with bright ambient light. Physiology and Behavior, 48, 317-320.

Civil Aviation Administration of China. (2005). Civil aircraft maintenance organization certification regulations, Part 145. Beijing, China: Statute of General Administration of Civil Aviation of China.

Civil Aviation Authority. (2002). An introduction to aircraft maintenance engineering human factors for JAR 66 (CAP 715). West Sussex, UK.

Civil Aviation Authority. (2003). Aviation maintenance human factors (EASA / JAR145 approved organisations): Guidance material on the UKCAA interpretation of Part-145 Human Factors and Error Management Requirements (CAP 716). West Sussex, UK. 
Civil Aviation Authority. (2009). Licensed Aircraft Maintenance Engineers - Personal responsibility when medically unfit or under the influence of drink or drugs. (Leaflet 15-6). In CAP 562 Civil Aircraft Airworthiness Information and Procedures. West Sussex, UK.

Civil Aviation Department. (2009). Maintenancepersonnel duty time limitations (Air Safety Circular, ASC 00-1). Malé, Republic of Maldives.

Civil Aviation Safety Authority. (2004). Notice of proposed rule making maintenance and maintenance personnel requirements (NPRM 0407MS). Canberra, Australian Capital Territory.

Civil Aviation Safety Authority. (2009a). Fatigue risk management systems. Civil Aviation Advisory Publication (CAAP 5.55-1). Canberra, Australian Capital Territory.

Civil Aviation Safety Authority. (2009b). Acceptable Means of Compliance $(A M C)$ and Guidance Material (GM) for CASR Part 145, Draft. Canberra, Australian Capital Territory.

Cook, B. (2008). Managing fatigue. Flight Safety Australia, 65, 22-26.

Dawson, D. (2000). Shift Maintenance: The role of fatigue in human error. Proceedings of the 14th Annual Human Factors in Aviation Maintenance Symposium, Vancouver, BC.

Dawson, D., Encel, N., \& Lushington, K. (1995). Improving adaptation to simulated night shift:Timed exposure to bright light versus daytime melatonin administration. Sleep, 18, 11-21.

Dawson, D., \& Fletcher, A. (2001). A quantitative model of work-related fatigue: Background and definition. Ergonomics, 44, 144-163.

Della Rocco, P., Comperatore, C., Caldwell, L., \& Cruz, C. (2000). The effects of napping on night shift performance (DOT/FAA/AM-00/10). Washington, DC: Office of Aviation Medicine.

Dinges, D. (1995). An overview of sleepiness and accidents. Journal of Sleep Research, 4, 4-14.

Dinges, D., Mallis, M., Maislin, G., \& Powell, J. (1998). Evaluation of techniques for ocular measurement as an index offatigue and the basis for alertness management (DOT HS 808 762). Washington, DC: National Highway Traffic Safety Administration.
Dinges, D., \& Powell, J. (1985). Microcomputer analysis of performance on a portable, simple visual RT task during sustained operations. Behavioral Research Methods Instruments and Computers, 17, 652-655.

Dupont, R., \& Dupont, G. (2010, March). The fit for work indicator - A new Safety Tool. Presentation to CHC Safety and Quality Summit, Vancouver, B.C. [Online] Available: http://www.system-safety.com/ fitforwork/OSPAT.htm

European Aviation Safety Agency. Part 145. Section 145.A.47 (b). Cologne, Germany.

European Aviation Safety Agency. (2003). Acceptable Means of Compliance $(A M C)$ and Guidance Material (GM) for EASA Part 145. Cologne, Germany.

European Aviation Safety Agency. (2009). Fatigue risk management system (FRMS). Notice of Proposed Amendment (NPA) No 200902C. Cologne, Germany.

Federal Aviation Administration. (2010). Fatigue risk management systems for aviation safety. Advisory Circular 120-103. Washington DC.

Federal Aviation Administration. (2011a). Safety management systems website. [On-line]. Available: www.faa. gov/about/initiatives/sms/

Federal Aviation Administration. (2011b). Fatigue countermeasures workshop for maintenance personnel. [CD-ROM]. Washington DC.

Ficca, G., Axelsson, J., Mollicone, D., Muto, V., \& Vitiello, M. (2010). Naps, cognition and performance. Sleep Medicine Reviews 14, 249-258.

Fletcher, A. (2007). The past present and future of fatigue risk management systems in Australian general aviation. [On-line]. Available at www.faidsafe.com/ news.htm.

Fletcher, A., \& Dawson, D. (2001). A quantitative model of work-related fatigue: Empirical evaluations, Ergonomics, 44, 475-488, 2001.

Folkard, S. (2003). Work hours of aircraft maintenance personnel (UK CAA Paper 2002/06). West Sussex, UK: Research Management Department, Safety Regulation Group.

Fourie, C., Holmes, A., Bourgeois-Bougrine, S., Hilditch, C., \& Jackson, P. (2010). Fatigue risk Management Systems: A review of the literature (Road Safety Research Report No. 110). London, UK: Department of Transport. 
Gertler, J., Popkin, S., Nelson, D., \& O’Neil, K. (2002). Toolbox for transport operator fatigue. Washington DC; National Academy Press.

Greeley, H., Berg, J., Friets, E., Wilson, J., Greenough, G., Picone, G., Whitmore, J., \& Nesthus, T. (2007). Fatigue estimation using voice analysis. Behavior Research Methods, 39, 610-619.

Hackworth, C., Holcomb, K., Banks, J., Schroeder, D., \& Johnson, W. (2007). A survey of maintenance human factors programs around the world. International Journal of Applied Aviation Studies, 7 , 212-231.

Hobbs, A., Williamson, A., \& Van Dongen, H.P. (2010). A circadian rhythm in skill-based errors in aviation maintenance. Chronobiology International, 27, 304-316.

Hoddes, E., Zarcone, V., Smythe, H., \& Dement, W. (1973). Quantification of sleepiness, a new approach. Psychophysiology, 10, 431-436.

Independent Transport Safety Regulator. (2010). Use of bio-mathematical models in managing risks of human fatigue in the workplace (Transport Safety Alert No. 34). State Government of New South Wales, Australia. Available at www.transportregulator.nsw.gov.au

International Civil Aviation Organization. (2003). Human factors guidelines for aircraft maintenance manual (ICAO Document 9824). Montreal, Canada.

International Civil Aviation Organization. (2008). A more proactive approach. The ICAO Journal - Vol 63, 15-19.

International Organization for Standardization. (2009). International standard on risk management - Risk assessment techniques (IEC/ISO 31010). Geneva, Switzerland.

Jauregui, F., \& Hosey, P. (2005). Extended work hours, maintenance. West Sussex, UK: International Federation of Airworthiness.

Jauregui, F., \& Hosey, P. (2007). Guidance information for the establishment of duty time limitations and rest periods. West Sussex, UK: International Federation of Airworthiness.

Johnson, W. (2008, June). Views of maintenance fatigue based mostly on FAA empirical studies. Proceedings of the FAA Fatigue Management Symposium: Partnerships for Solutions, Vienna, VA.
Johnson, W., Mason, F., Hall, S., \& Watson, J. (2001). Evaluation of aviation maintenance working environments, fatigue, and human performance. Retrieved from https://hfskyway.faa.gov/HFTest/ Bibliography\%20of\%20Publications $\% 5$ CMX\%20 FAA(Former\%20HFSkyway)\%5CDocument $\% 20$ List\%5CEvaluation\%20of\%20aviation\%20Maintenance $\% 20$ Working $\% 20$ Environments, $\% 20$ Fatigue, $\% 20$ and $\% 20$ Human $\% 20$ Performance.pdf

Klein, M. (1997). The shiftworkers' handbook. Lincoln, NE: Synchrotech.

Kryger, M.H., Roth, T., \& Dement, W.C. (Eds.) (2005). Principles and practice of sleep medicine. Philadelphia, PA: Elsevier.

Macchi, M., Boulos, Z., Ranney, T., Simmons, L., \& Campbell, S. (2002). Effects of an afternoon nap on nighttime alertness and performance in longhaul drivers. Accident Analysis and Prevention, 34, 825-834.

Mallis, M.M., Mejdal S., Nguyen T.T., \& Dinges D.F. (2004). Summary of the key features of seven biomathematical models of human fatigue and performance. Aviation, Space and Environmental Medicine, 75 (3 Suppl): A4-14.

Mitler, M.M., Carskadon, M.A., Czeisler, C.A., Dinges, D.F., \& Graeber, R.C. (1988). Catastrophes, sleep and public policy: Consensus report. Sleep, 11, 100-109.

Mitler, M.M., \& O’Malley, M.B. (2007). Wake-promoting medications: Efficacy and adverse effects. In M. Kryger, T. Roth, and W. Dement (Eds.), Principles and practice of sleep medicine (pp. 484-498). Philadelphia, PA: Elsevier.

Moore-Ede, M. (1993). The 24 hour society. London, UK: Piatkus.

National Center for Biotechnology Information. (2008). Modafinil. [On-line]. Available: http://www.ncbi. nlm.nih.gov/pubmedhealth/PMH0000196.

National Transportation Safety Board. (1997). Recommendation A-97-71. Washington, DC.

National Transportation Safety Board. (2004). Loss of pitch control during takeoff. Air Midwest Flight 5481. Raytheon (Beechcraft) 1900D, Charlotte, North Carolina, January 8, 2003. (NTSB/AAR-04/01). Washington, DC. 
New Zealand Civil Aviation Authority. (2007). General maintenance rules. Rule Part 43.53. Wellington Petone, New Zealand.

Parliament of Australia. (2000). Beyond the midnight oil. An inquiry into managing fatigue in transport. Canberra, Australian Capital Territory: House of Representatives Standing Committee on Communication, Transport and the Arts.

Purnell, M.T., Feyer, A.M., \& Herbison, G.P. (2002). The impact of a nap opportunity during the night shift on the performance and alertness of 12-h shift workers. Journal of Sleep Research, 11, 219-227.

Reason, J. (1990). Human error. Cambridge University Press.

Reason, J., \& Hobbs, A. (2003) Managing maintenance error: A practical guide. Ashgate: Aldershot.

Reyner, L.A., \& Horne, J.A. (1997). Suppression of sleepiness in drivers: Combination of caffeine with a short nap. Psychophysiology, 34, 721-725.

Rhodes, W., Lounsbury, R., Steele K., \& Ladha, N. (2003). Fatigue risk assessment of aircraft maintenance tasks (TP 14169E). Ottawa, Ontario: Transport Canada.

Rosekind, M.R., Graeber, R.C., Dinges, D.F., Connell, L.J., Rountree, M.S., Spinweber C.L., \& Gillen, K.A. (1994). Crew factors in flight operations: Effects of planned cockpit rest on crew performance and alertness in long haul operations (NASA Technical Memorandum 108839). Moffett Field, CA: NASA Ames Research Center.

Stewart, S., \& Holmes, A. (2008, April). Limitations on hours of work and fatigue risk management. Proceeding of the $9^{\text {th }}$ Society of Petroleum Engineers International Conference on Health, Safety, and Environment in Oil and Gas Exploration and Production, Nice, France.

Tabak, B., \& Raslear, T.G. (2010). Procedures for validation and calibration of human fatigue models: The fatigue audit interdyne tool (DOT/FRA/ORD-10/14). Washington DC: Federal Railroad Administration.

Thorne, D.R., Johnson, D.E., Redmond, D.P., Sing, H.C., Belenky G., \& Shapiro, J. (2005). The Walter Reed palm-held psychomotor vigilance test. Behavior Research Methods. 37, 111-118.

Transport Canada. (2007a). Fatigue risk management system for the Canadian Aviation Industry. Developing and implementing a fatigue risk management system (TP 14575E). Ottawa, Ontario.

Transport Canada. (2007b). An introduction to managing fatigue (TP 14572E). Ottawa, Ontario.

Transport Canada. (2007c). Fatigue management strategies for employees (TP 14573E). Ottawa, Ontario.

Transport Canada. (2007d). Advisory circular on the development and implementation of fatigue risk management systems in the Canadian aviation industry (AC No.: SUR-001). Ottawa, Ontario.

Van Dongen, H.P.A., Price, N.J., Mullington, J.M., Szuba, M.P., Kapoor, S.C., \& Dinges, D.F. (2001). Caffeine eliminates psychomotor vigilance deficits from sleep inertia. Sleep, 24, 813-819.

Walsh, J.K., Randazzo, A.C., Stone, K.L., \& Schweitzer, P.K. (2004). Modafinil improves alertness, vigilance and executive functioning during simulated night shifts. Sleep, 27, 434-439.

Wertz, A.T., Ronda, J.M., Czeisler, C.A., \& Wright, K.P. (2006). Effects of sleep inertia on cognition. Journal of the American Medical Association, 295, 163-164.

Wilkinson, R.T. (1965). Sleep deprivation. In O.G. Edholm, \& A. Bacharach (Eds.), The physiology of human survival (pp. 399-430). New York: Academic.

Williamson, A., \& Chamberlain, T. (2005). Review of on road driver fatigue monitoring devices. Kensington, Australia: University of New South Wales, Injury Risk Management Research Centre. 


\section{APPENDIX A}

Model Rest and Duty Limitations for Persons Performing Maintenance Functions on AOC Holder Aircraft

1. No person may assign, nor shall any person perform maintenance functions for aircraft certified for commercial air transport, unless that person has had a minimum rest period of eight hours prior to the beginning of duty.

2. No person may schedule a person performing maintenance functions for aircraft certified for commercial air transport for more than 12 consecutive hours of duty.

a. In situations involving unscheduled aircraft unserviceability, persons performing maintenance functions for aircraft certified for commercial air transport may be continued on duty for- Up to 16 consecutive hours; or

b. 20 hours in 24 consecutive hours.

3. Following unscheduled duty periods, the person performing maintenance functions for aircraft shall have a mandatory rest period of 10 hours.

4. The AOC holder shall relieve the person performing maintenance functions from all duties for 24 consecutive hours during any seven consecutive day period. 



\section{APPENDIX B}

\section{Folkard's (2003) Recommendations on Aircraft Maintenance Hours of Service}

a) No scheduled shift should exceed 12 hours.

b) No shift should be extended beyond a total of 13 hours by overtime.

c) A minimum rest period of 11 hours should be allowed between the end of shift and the beginning of the next, and this should not be compromised by overtime.

d) A maximum of fours hours' work before a break.

e) A minimum break period of 10 minutes plus five minutes for each hour worked since the start of the work period or the last break.

f) Scheduled work hours should not exceed 48 hours in any period of seven successive days.

g) Total work, including overtime, should not exceed 60 hours, or seven successive work days, before a period of rest days.

h) A period of rest days should include a minimum of two successive rest days continuous with the 11 hours off between shifts (i.e., a minimum of 59 hours off). This limit should not be compromised by overtime.

i) To comply with the European Union Working Time directive, four weeks of annual leave should be allowed.

j) A span of successive night shifts should be limited to six for shifts of up to eight hours long, four for shifts of 8.1 to 10 hours long, and two for shifts of 10.1 hours or longer. These limits should not be exceeded by overtime.

k) A span of nights shifts involving 12 or more hours of work should be immediately followed by a minimum of two successive rest days continuous with the 11 hours off between shifts (i.e., a minimum of 59 hours off), and this should be increased to three successive rest days (i.e., 83 hours off) if the preceding span of night shifts exceeds three, or 36 hours of work. These limits should not be compromised by overtime.

1) The finish time of the night shift should not be later than 0800 .

m) A morning or day shift should not be scheduled to start before 0600 and, wherever possible should be delayed to start between 0700 and 0800 .

n) A span of successive morning or day shifts that start before 0700 should be limited to four, immediately following which there should be a minimum of two successive rest days continuous with the 11 hours off between shifts (i.e. a minimum of 59 hours off). This limit should not be compromised by overtime.

o) Wherever possible aircraft maintenance engineers should be given at least 28 days notice of their work schedule.

p) Employers of aircraft maintenance personnel should consider developing risk management systems similar to those required by Western Australia's Code of Practice for commercial vehicle drivers.

q) Educational programs should be developed to increase aircraft maintenance engineers' awareness of the problems associated with shiftwork. In particular, it is important to draw their attention to the objective trends in risk with a view to increasing their vigilance at points when risk may be high despite the fact that fatigue may not be. It is also important to provide information on how to plan for nightwork, and to give guidance on the health risks which seem to be associated with shift work, particularly at night.

r) Aircraft maintenance personnel should be required to report for duty adequately rested.

s) Aircraft maintenance personnel should be discouraged or prevented from working for other organizations on their rest days, and hence from exceeding the proposed recommendations on work schedules despite their implementation by their main employer. 



\section{APPENDIX C}

International Federation of Airworthiness Recommendations on Duty Times for Aviation Maintenance

1 A scheduled shift should not normally exceed 12 hours.

2 A shift should not be extended beyond a total of 16 hours, including overtime.

3 Scheduled duty work, including break time(s), standby and overtime, should not exceed a maximum of 72 hours in any successive 7 day period.

4 The period of work before a scheduled break should be a maximum of 4 hours.

5 Minimum break period(s) of 10 minutes, plus 5 minutes for each hour worked, to a maximum of 30 minutes should be scheduled and utilized. The process begins after every 30 minute break is taken.

6 Scheduled night shifts should be limited to no more than 6 days in each 7 calendar days of 8 hour durations, or 4 days in each 7 calendar days of 12 hour durations, including overtime.

7 Night shifts involving 12 hours duty, including breaks and overtime, should allow a minimum of 9 hours opportunity of uninterrupted rest prior to reporting to the next scheduled shift start time.

8 Normal shifts of 8 hours duty, 5 days in each 7 calendar days should allow a minimum of 9 hours of uninterrupted opportunity for rest prior to the reporting to the next scheduled shift start time.

Rest Period (s):

A Rest Period should be an uninterrupted and defined period of time during which an individual is free of all work and/or standby duties. It should allow the opportunity for a minimum of 8 hours of uninterrupted sleep before reporting to the next scheduled duty time. Also, it should include a minimum of 2 days, i.e. 48 continuous hours, between each scheduled weekly duty period, such as those detailed in paragraph 6 above. 



\section{APPENDIX D}

Fatigue Policy of Airline B

1. No planned shift to exceed 12 hours,

2. No actual shift be extended beyond a total of 13 hours,

3. Planned working hours should not exceed 48 hours in any 7 consecutive days,

4. Actual working hours, including overtime, should not exceed 60 hours in any period of 7 consecutive days before an extended rest period (refer below),

5. The number of planned or actual consecutive shifts should be limited to 6 and immediately followed by an extended rest period (refer below),

6. Shift start times should always rotate forward from day to afternoon to night,

7. A minimum rest period of 10 hours should be allowed between the end of one shift and the beginning of the next. A block of night shifts should be immediately followed by an extended rest period,

8. An extended rest period should include a minimum of 2 consecutive rest days continuous with the minimum rest period of 10 hours associated with the last shift worked (58 hours),

9. As a minimum, the last 24 hours of any extended rest period should not be available for overtime,

10. Any planned single day off between blocks of shifts should not be available for overtime, and

11. A minimum of 20 days annual leave should be provided each employee and taken. 



\section{APPENDIX E}

A Fatigue Risk-Assessment System in use by a Maintenance Organization

\begin{tabular}{ll}
\hline Away From Base & 2 \\
Yes & 1 \\
No &
\end{tabular}

Travel between shifts

Local, Less than 20 mins 1

Travel Time up to 45 mins 2

Travel Time over 45 mins 3

Type of work carried out in last 4 days

Normal 1

Confined Space $\quad 2$

Heavy physical 3

Type of work to be undertaken

Normal 1

Confined Space $\quad 2$

Heavy Physical 3

Duration of task

$0-5 \mathrm{Hrs}$

5-10 hrs 2

10-15 hrs 3

In excess of $15 \mathrm{hrs} \quad 4$

$\underline{\text { Risk Factor }}$

LOW 1 -- 6

Can continue to work with normal supervision.

MED 7--12

Can continue work but must be closely supervised

HIGH $13--18$

This work can only be carried out by this individual. Supervision must be of the highest quality. All personnel must be briefed by the Project Manager. 



\section{APPENDIX F}

Self-Assessment Scales

Stanford Sleepiness Scale (Hoddes et al., 1973).

\begin{tabular}{|l|l|}
\hline Code & Scale statements \\
\hline 1 & Feeling active and vital, alert, wide awake \\
\hline 2 & Functioning at a high level but not at peak; able to concentrate \\
\hline 3 & Relaxed, awake, responsive, not at full alertness \\
\hline 4 & A little foggy, not at peak, let down \\
\hline 5 & Fogginess, beginning to lose interest in remaining awake; slowed down \\
\hline 6 & Sleepiness, prefer to be lying down, fighting sleep, woozy \\
\hline 7 & Almost in a reverie, sleep onset soon, lost struggle to remain awake. \\
\hline
\end{tabular}

Karolinska Sleepiness Scale (Akerstedt \& Gillberg, 1990).

Which statement best describes your sleepiness during the previous five (5) minutes? Please check the appropriate box below.

\begin{tabular}{|l|l|}
\hline Code & Scale statements \\
\hline 1 & Very alert \\
\hline 2 & \\
\hline 3 & Alert, normal level \\
\hline 4 & \\
\hline 5 & Neither alert nor sleepy \\
\hline 6 & \\
\hline 7 & Sleepy, but no effort to keep awake \\
\hline 8 & \\
\hline 9 & Very sleepy, great effort to keep awake \\
\hline
\end{tabular}





\section{APPENDIX G}

International Federation of Airworthiness Fatigue Control Recommendations

From International Federation of Airworthiness document: Extended Work Hours, Maintenance (Jauregui \& Hosey, 2005).

Persons who are in leadership positions are required to adhere to the following criteria:

Certificated/authorized individuals who are on duty 12 hour continuous hours, without adequate rest, and who are involved with repairs or return to service activities, may NOT inspect or accomplish the return to service certification actions and/or critical in process inspection, unless they have had at least 8 hours of rest (off-duty time) since the last duty period, if that last period was over 12 hours on duty.

In addition, individuals accomplishing maintenance work may not work, or be on duty, more than 24 continuous hours, without at least 8 hours of off-duty time to rest. 
